\section{POTENTIAL EFFECT ON CANCER OF IMPROVED DIET AND INCREASED EXERCISE}

The Australian Institute of Health and Welfare has estimated that 9.2 per cent of cancer deaths in 1996 were attributable to an intake of less than five servings a day of fruit and vegetables, 6.6 per cent were due to lack of any vigorous physical activity, 3.0 per cent were due to having a body mass index of 25 or more, and 3.6 per cent were due to intake of alcohol at any level. ${ }^{2}$ Since these estimates were generally conservative and do not include all possible sources of dietary or energy balance impact on cancer risk, the resulting total estimate, 22 per cent of cancer deaths attributable to diet or lack of exercise, is probably a minimum estimate.

This estimate accords reasonably well, therefore, with other estimates of 30-40 per cent of cancer deaths being preventable by dietary and related means.

\section{CONCLUSION}

Dietary and related energy balance factors have an important effect on cancer incidence and mortality in Australia. While the estimated effect is not as great as that of tobacco smoking (26 per cent of cancer deaths in 1996 due to smoking, as estimated by the Australian Institute of Health and Welfare), ${ }^{2}$ the real effect may be as great or greater. Therefore, effective implementation of the Cancer Council guidelines for prevention of cancer by diet and exercise, or similar guidelines, would be expected to yield substantial benefit.
Moreover, these guidelines generally sit well with more general dietary advice, which is designed to reduce the risk of cardiovascular disease and diabetes as well. It is time that improved diet and increased exercise were more consistently and effectively promoted by public health agencies in Australia.

\section{REFERENCES}

1. Doll R, Peto R. The causes of cancer-quantitative estimates of avoidable risks of cancer in the United States today. J Natl Cancer Inst 1981; 66:1195-1308.

2. World Cancer Research Fund and the American Institute for Cancer Research. Food, Nutrition and the Prevention of Cancer: a Global Perspective. New York: American Institute for Cancer Research, 1997.

3. Working Group on Diet and Cancer of the Committee on Medical Aspects of Food and Nutrition Policy. Nutritional Aspects of the Development of Cancer. London: The Stationery Office. 1998.

4. Mathers C, Vos T, Stevenson C. The burden of disease and injury in Australia. Canberra: Australian Institute of Health and Welfare, 1999.

5. Slavin J, Jacobs D, Marquart L. Whole-grain consumption and chronic disease: protective mechanisms. Nutr Cancer 1997; 27:14-21.

6. National Health and Medical Research Council. The prevention, early detection and management of colorectal cancer. Canberra: Australian Government Publishing Service, 1999.

7. National Health and Medical Research Council. Acting on Australia's weight: a strategic plan for the prevention of overweight and obesity. Canberra: Australian Government Publishing Service, 1997.

\title{
INCREASING THE CONSUMPTION OF VEGETABLES AND FRUIT: A NATIONAL PUBLIC HEALTH CALLTO ACTION
}

Philip Vita, Jane Moxon and Edwina Macoun Health Promotion Branch

NSW Department of Health

There is a need for national public health action to increase fruit and vegetable consumption for the protection and prevention of chronic disease, including many cancers. There has never been a better time to advance public health nutrition in Australia. The impetus has been provided by the Strategic Inter-Governmental Nutrition Alliance (SIGNAL) through the National Public Health Partnership, which has developed a national framework for action in public health nutrition EAT WELL Australia: An agenda for action for public health nutrition 20002010. As part of this, SIGNAL has developed a National Action Plan to promote the consumption of vegetables and fruit. ${ }^{1}$ This articles outlines the key components of the National Action Plan, and the role of the NSW Department of Health to increase vegetable and fruit consumption to ensure that the effect of diet-related disorders, including cancer, is reduced.

\section{BACKGROUND}

There is compelling evidence that consumption of vegetables and fruit offers protection against many cancers, including colorectal and stomach cancers. ${ }^{2}$ The challenge for public health is to develop effective and sustainable initiatives. Dietary behaviour is very complex and not well understood. Diet is influenced by a myriad of individual, social, economic and environmental factors. Moreover, it is inherently difficult to monitor-and consequently to assess-change. To improve population health through dietary interventions it is important to consider the supply-demand balance for food products in our community (Figure 6). It is crucial that policies and programs concurrently increase consumer demand for healthier foods, as well as address structural barriers to access and supply. ${ }^{3}$ 


\section{Strategic Inter-Governmental Nutrition Alliance (SIGNAL)}

The Strategic Inter-Governmental Nutrition Alliance (SIGNAL) is a national partnership with representatives from the Commonwealth, State and Territory Health Departments, National Health and Medical Research Council (NHMRC), Australian Institute of Health and Welfare (AIHW), and the Australian and New Zealand Food Authority (ANZFA), together with external experts and Aboriginal and Torres Strait Islander representatives. It was formed by the National Public Health Partnership in 1997 to coordinate action to improve the nutritional health of Australians. The primary goal of SIGNAL is to provide strategic direction and coordination of national nutrition initiatives. These initiatives are described fully on the Web site www.dhs.vic.gov.au/nphp/signal. SIGNAL has developed Eat Well Australia: An Agenda for Action in Public Health Nutrition, 2000-2010. Key initiatives for health gain include:

- improving nutrition for vulnerable groups and Aboriginal and Torres Strait Islander peoples;

- promoting vegetable and fruit consumption; healthy weight; and good nutrition for mothers, infants and school-aged children.

SIGNAL has several working groups, including the Vegetable and Fruit Working Party, which has developed a National Action Plan for increasing the consumption of vegetables and fruit.

\section{National Action Plan to increase consumption of vegetables and fruit 2000-2005}

The National Action Plan to increase the consumption of vegetables and fruit 2000-2005 was developed through a rigorous process that utilised current evidence of the benefits of increased consumption of vegetables and fruit; and strategies to increase consumption. ${ }^{5}$ Consultation with the vegetable and fruit industry, and non-government organisations, resulted in an iterative process that was able to incorporate potential opportunities for future collaborative work.

\section{FIGURE 6}

THE FOOD SUPPLY_DEMAND BALANCE

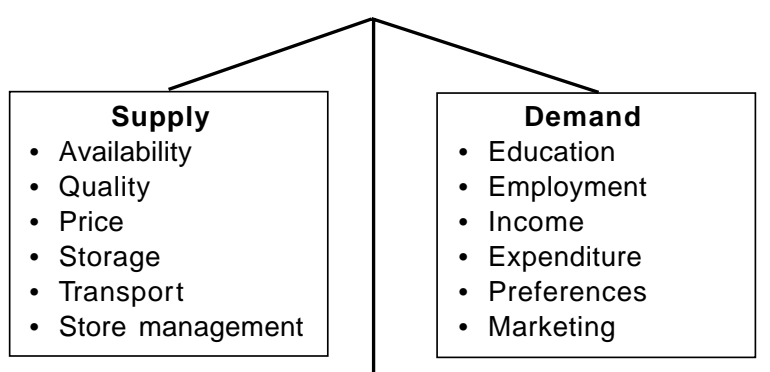

An evidence-based portfolio of interventions was developed that describes effective, realistic and comprehensive approaches to promoting increased consumption of vegetables and fruit. ${ }^{6}$ The portfolio comprises policy interventions, program interventions and infrastructure support mechanisms. A summary of the priority areas in the National Action Plan is displayed in Table 1. The main components identified in the three portfolio areas are briefly outlined below.

\section{POLICY INTERVENTIONS}

The policy interventions identified include a range of national position statements and consumption guidelines for the population, as well as position papers on vegetable and fruit consumption and the prevention of disease. In addition, a study of the effect of government policies, other than health, on consumption of vegetables and fruit; and also feasibility studies on a tax rebateincentive system for suppliers and transport operators in rural and remote areas were suggested. Food policy programs, such as Aboriginal Community Store policies in rural and remote areas have already improved the availability, quality and pricing, and led to increased sales of vegetables and fruit. ${ }^{7}$

\section{PROGRAM INTERVENTIONS}

Key settings for program interventions include:

- schools

- childcare

- health providers

- point of sale

- institutional and commercial food services.

The scope of interventions is wide and includes:

- social marketing, such as media advertising, public relations and point of sale promotion;

- food supply initiatives, such as actions and policies by suppliers, transport companies and retailers to increase access to quality vegetables and fruit;

- community interventions, such as a 'vegetables and fruit week' and other community based promotions;

- school programs and primary health care interventions.

\section{INFRASTRUCTURE SUPPORT}

The strategies identified to underpin the program and policy interventions focused on system development and building the capacity of the public health workforce. Many of the programs require effective partnerships with other sectors, the food industry, non-government organisations and community groups. An inter-governmental approach is also needed, to work collaboratively with the education and agriculture sectors. Public health nutrition infrastructure needs building in all states, and particularly in NSW, if a significant effect is to be achieved on the public health consequences of poor and inadequate nutrition. The capacity building framework, and indicators developed for health promotion, are useful 


\section{TABLE 1}

\section{SUMMARY OF THE NATIONAL ACTION PLAN TO INCREASE THE CONSUMPTION OF VEGETABLES AND FRUIT}

2000-2005'

\begin{tabular}{|c|c|c|}
\hline Priority Area & Priority actions & Examples of action \\
\hline National Promotion & $\begin{array}{l}\text { Establish a collaborative partnership with } \\
\text { industry and develop and implement a } \\
\text { national communication strategy. }\end{array}$ & $\begin{array}{l}\text { - } \text { position statement; } \\
\text { - consumption guidelines; } \\
\text { - develop promotional strategies (that is, } \\
\text { market research social marketing, point of } \\
\text { sale advertising). }\end{array}$ \\
\hline Food Supply & $\begin{array}{l}\text { Map the vegetable and fruit supply and } \\
\text { develop strategies to overcome supply } \\
\text { issues particularly for vulnerable groups. }\end{array}$ & $\begin{array}{l}\text { - Establish a monitoring system; } \\
\text { - strategies developed and implemented. }\end{array}$ \\
\hline Community & Collect and disseminate effective programs. & $\begin{array}{l}\text { - Best practice guidelines for the promotion of } \\
\text { vegetables and fruit. }\end{array}$ \\
\hline \multirow{2}{*}{ Schools } & $\begin{array}{l}\text { Provide funding for demonstration community } \\
\text { programs. }\end{array}$ & - grant program funding is investigated. \\
\hline & $\begin{array}{l}\text { A coordinated integrated approach to the } \\
\text { promotion of vegetables and fruit in schools } \\
\text { involving curriculum, the school environment } \\
\text { and the community. }\end{array}$ & $\begin{array}{l}\text { - } \text { resources identified or developed and } \\
\text { disseminated; } \\
\text { - a health promoting schools framework is } \\
\text { used to guide school based initiatives. }\end{array}$ \\
\hline
\end{tabular}

tools to assist this with this. ${ }^{8}$ Working in a coordinated way; and advocating strongly for organisational development, workforce development and adequate public health nutrition investment, are paramount. The establishment of the NSW Centre for Public Health Nutrition, based at Sydney University, is one example of improved infrastructure that is contributing to better planning, research, information and monitoring in public health nutrition. ${ }^{9}$

\section{WHERETO NEXT?}

The NSW Department of Health is making a significant contribution, and is about to disseminate a toolkit of tasting events to guide public health nutritionists in promoting vegetable and fruit consumption in community settings. ${ }^{10}$ A nutrition strategy Eat Well NSW 2001-2005, ${ }^{11}$ currently being developed in line with Healthy People $2005,{ }^{12}$ is defining the action areas for public health nutrition investment in NSW, and focuses on the promotion of vegetable and fruit consumption. The NSW Centre for Public Health Nutrition is supporting the implementation of state nutrition initiatives through: planning advice; research; workforce development, and monitoring in public health nutrition. Taken as a whole, these factors provide opportunities to facilitate and extend the partnerships between governments, non-government organisations and private industry to ensure that evidencebased strategies are implemented, that vegetable and fruit consumption is increased, so that the effect of diet-related disorders, including cancer, is reduced.

\section{REFERENCES}

1. SIGNAL, National Action Plan to increase the consumption of vegetables and fruit 2001-2005 www.dhs.vic.gov.au/nphp/signal.

2. CSIRO Health Sciences and Nutrition. The relationship between the consumption of fruits and vegetables and health status, 1999. www.dhs.vic.gov.au/nphp/signal.

3. McComb J, Webb K, and Marks G. What do we mean by 'Food Access' and 'Food Supply'? Foodchain, March 2000. SIGNAL Web site.

4. National Nutrition Survey. Foods eaten. Australia 1995. Canberra: AGPS, 1996. ABS Catalogue no: 4804.0.

5. Report to the Commonwealth Department of Health and Aged Care for SIGNAL. An issues paper on barriers to the consumption of fruits and vegetables, and previous efforts to promote an increased consumption of fruits and vegetables. Canberra: CSIRO Human Nutrition, 1999 (unpublished).

6. Public Health Planning and Practice Improvement. An Intervention Portfolio To Promote Fruit and Vegetable Consumption. Part 1: The Process and Portfolio. Melbourne: National Public Health Partnership, 2000. www.dhs.vic.gov.au/nphp/signal.

7. Clarey N, Groos A, and Leonard D. The components of a successful nutrition strategy for aboriginal Community Stores in Queensland. Conference proceedings, Nutrition Networks, August 1999, Cairns, Queensland.

8. Hawe P, King L, Noort M, Jordens C, and Lloyd B. Indicators to help with capacity building in health promotion. NSW Department of Health and the Australian Centre for Health Promotion, Department of Public Health and Community Medicine, University of Sydney, 2000.

9. Moxon J, Macoun E, and Vita P. NSW Health establishes the Centre for Public Health Nutrition. NSW Public Health Bulletin 2000; 11 (7): 127.

10. NSW Department of Health. Fruit and Vegetable Toolkit: A guide for local tasting events. Sydney: NSW Department of Health, 2001 (in press).

11. NSW Department of Health. Eat Well NSW 2001-2005: A public health nutrition strategy for NSW Health and nongovernment organisations (Discussion paper). Sydney: NSW Department of Health, 2001.

12. Public Health Division. Healthy People 2005: New Directions for Public Health in NSW. Sydney: NSW Department of Health, 2000. 